\title{
COMUNIDADES TRANSNACIONAIS: PARTICIPAÇÃO E INTEGRAÇÃO
}

\author{
Maria Ortelinda BARROS GONÇALVES \\ Universidade Portucalense. CEPESE
}

\section{INTRODUÇÃO}

As migrações internacionais não são uma invenção do século XX ou da modernidade, mas fazem parte da história da humanidade. Contudo têm aumentado em volume e significância, desde 1945, e mais particularmente, desde meados dos anos 80. SiMMONS (1987) sustenta que os padrões de migração contemporâneos reflectem duas importantes dimensões: instabilidade e nova estrutura de oportunidades económicas que emergem com a acumulação flexível. Neste contexto, as migrações internacionais são actualmente temporárias, circulares, globais e reguladas, obrigando os actores internacionais a criar novas grelhas de leitura.

A contextualização do processo migratório contemporâneo não se reduz a um mero fluxo de pessoas e/ou trabalhadores mas integra um importante intercâmbio de bens materiais e simbólicos, isto é, de recursos económicos, culturais, sociais e políticos, entre os territórios de origem e de acolhimento. Em virtude do desenvolvimento dos meios de transporte e das novas tecnologias de informação, os migrantes não são mais "enraizados"; em vez disso, movem-se num espaço interfronteiras internacionais e entre culturas e sistemas sociais (GLICK e SCHILLER 1997; LEVIT 1998), adoptando estratégias de vida bi e ou multinacionais e bi e ou multi-culturais, como reconhecimento de múltiplas afiliações e identidades. Estes migrantes incorporam não só as remessas económicas mas também as remessas sociais para as suas terras de origem, impulsionando estas à mudança. Hoje, no limiar no séc. XXI, esta nova vertente da migração internacional é pautada pela criação de pontes de encontro, de redes entre sociedades distintas, com base nas novas tecnologias de comunicação e informação.

Os migrantes no mundo transnacional e global estão envolvidos na construção da nação de mais de que um Estado. As entidades nacionais não são só ofuscadas mas também negociadas ou construídas. 
Embora os migrantes tenham experiências comuns, a própria migração é um fenómeno diverso e complexo. Os migrantes podem ser diferenciados pelo género, classe social e etnicidade, e pela razão da migração, pela idade, pela forma de migração, pela natureza e influência na economia global.

As migrações internacionais são um dos principais factores de transformação e de desenvolvimento dos países e/ou regiões. Um conhecimento mais vasto sobre os fluxos migratórios internacionais, a nível das consequências e impactos nos países emissores e receptores, contribuirá certamente para a compreensão da nova ordem do séc. XXI.

O presente trabalho refere-se à análise dos resultados de um inquérito dirigido a 300 indivíduos de uma região rural periférica do norte de Portugal (região barrosã) em percurso emigratório.

\section{ANÁLISE SOCIODEMOGRÁFICA DA AMOSTRA}

\subsection{Género/idade}

Foram validados 276 inquéritos, sendo $68,4 \%$ dos sujeitos do sexo masculino (188 casos) e 31,6\% do sexo feminino ( 87 casos). Foi inquirido um subconjunto específico diferenciado da restante população, os lusodescendentes. Estes representam 25 indivíduos, ou seja, cerca de $9,1 \%$ da totalidade da amostra, situando-se a maioria no escalão de menos de 25 anos (13 casos, 54,2\%). A média etária dos lusodescendentes é de 25,5 anos, com um desvio padrão de 5,2 anos, sendo a idade mais baixa considerada 19 anos.

A amostra na totalidade apresenta uma média etária de 41,1 anos, obtida num intervalo de 53 anos, com valor mínimo de 19 anos e máximo de 72 (desvio padrão de 13,7 anos). A sua distribuição é, assim, de alguma forma homogénea pelos vários grupos etários, com percentagens que variam entre os 15,7\% (43 casos), para os inquiridos de menos de 25 anos, e os $26,3 \%$ ( 72 casos), para o grupo etário dos 26 aos 35 anos. É de referir igualmente que a maioria dos inquiridos (80,3\%) se enquadra na população activa, contra apenas $19,7 \%$ de sujeitos com idades superiores a 56 anos.

\subsection{Nacionalidade}

A nacionalidade portuguesa aparece com a percentagem de $92,4 \%$ (255 casos), surgindo em segundo lugar, e apenas como referência, a nacionalidade francesa, com 4,3\% (12 casos, dos quais 6 são lusodescendentes). Dos 25 lusodescendentes inquiridos, 14 apresentam como $1^{\mathrm{a}}$ nacionalidade a portuguesa. Constata-se que emigração de segunda geração não obtém ou adopta necessariamente a nacionalidade do país de acolhimento/naturalidade. 
Em apenas 49 casos, podemos observar uma segunda cidadania, embora não se possa confundir esta com o estatuto específico da dupla-cidadania pois, nem sempre as situações observadas correspondem legalmente a esta denominação, como no caso dos Estados Unidos da América. Emergem assim a "dupla" nacionalidade francesa em 32,7\% (16 casos, com 6 lusodescendentes incluídos, e a brasileira com $14,3 \%$ ( 7 casos) dos sujeitos inquiridos.

\subsection{Habilitação literária}

Os dados recolhidos permitem, num primeiro momento, evidenciar que os sujeitos não possuem mais do que a escolaridade coincidente com os graus obrigatórios de ensino, ou seja, $74,2 \%$ ( 201 casos) com o $3^{\circ}$ Ciclo do ensino básico. É de referir que, destes, a grande maioria - 42,8\%- apenas concluiu o $1^{\circ}$ grau de ensino. Por sua vez, o ensino médio/superior apenas representa 5,9\% do total da amostra, demonstrando o fraco índice escolar apresentado pela população inquirida. É de salientar igualmente que a inclusão de lusodescendentes no estudo representa forte influência nos valores percentuais dos graus mais elevados da amostra (principalmente nos licenciados).

\section{SITUAÇÃO PROFISSIONAL - PASSADO E PRESENTE}

As profissões desempenhadas pelos inquiridos antes de emigrarem encontram-se ordenadas por sectores de actividade. Dois pontos essenciais sobressaem desta análise: em primeiro lugar, quase a maioria dos inquiridos, 49,8\% (110 casos), exercia uma profissão directamente ligada à agricultura; em segundo lugar, a proporção de indivíduos que se encontravam inactivos era de 25,3\% (56 casos). Estes últimos encontravam-se divididos em 3 situações distintas: 2 desempregados, 38 ainda inseridos no contexto escolar e 16 com trabalho doméstico.

Outro sector que detém alguma importância é o da construção civil e obras públicas, com $15,4 \%$ dos casos. Os restantes sectores juntos não representam mais de $10 \%$ da amostra total e, por isso, não têm a mesma representação do que os supra referidos. As condições de trabalho no momento anterior à emigração permite-nos analisar o efeito do trajecto dos inquiridos nas suas carreiras profissionais, ajudando-nos a entender até que ponto a integração no mercado de trabalho do país de acolhimento se fundamenta no tecido do país de origem.

A primeira profissão dos inquiridos, nos respectivos sectores de actividades no país de imigração, distribui-se, de forma diferenciada, em relação à desempenhada no país de origem. No primeiro emprego no país de acolhimento, apenas $14,2 \%$ (39 casos) permaneceram ligados à actividade agrícola, contra os $49,8 \%$ referidos anteriormente. Os restantes sectores mais aglutinadores são a construção civil, com $29,9 \%$ ( 82 casos) e o comércio e a hotelaria, com 17,9\% 
(49 casos). É possível evidenciar que o percurso migratório teve repercussões importantes nas profissões exercidas pelos inquiridos, registando-se mobilidade social horizontal, uma vez que estes, maioritariamente ligados à agricultura em Portugal, integraram principalmente funções de assalariados dependentes na construção civil, comércio e hotelaria, no seu primeiro contacto com o mercado de trabalho do país de destino. Esta tendência assume especial consistência no momento em que se analisa a situação laboral actual dos indivíduos. Estes, proporcionalmente, continuam a exercer uma profissão ligada à construção civil $(26,8 \%)$, ao comércio e hotelaria $(19,7 \%)$ e aos transportes e comunicações em $(16,0 \%)$, num total de 269 casos considerados. Por outro lado, o sector agrícola perde ainda mais representatividade, com apenas $7,1 \%$ contra os cerca de $40 \%$ em Portugal. As outras situações, com 18,2\%, acabam por englobar as situações de inactividade (reformados, desempregados ou outros). Os imigrantes incorporam profissões estigmatizadas resultantes da resistência, culturalmente condicionada, dos trabalhadores motivados em aceitar trabalhos servis, (PIORE, 1979; SASSEN, 1989). Estes dados em análise podem ser complementados com a análise da situação actual da profissão dos inquiridos, em que podemos observar que $70,1 \%$ trabalham como assalariados por conta de outrem (190 casos) e apenas $15,5 \%$ desempenham uma actividade económica por conta própria. "As oportunidades empresariais nem sempre estão disponíveis e transparentes para todos os imigrantes" (KLOOSTREMAN, 2000, p. 93). Segundo Light e Gold (2000), "a classe social do imigrante pode determinar o acesso desigual a oportunidades comunitárias". As oportunidades não estão igualmente distribuídas. O emigrante urbano de classe mais alta, em particular aquele que traz consigo uma mais elevada herança de capital cultural, é mais provável que tenha sucesso na hierarquia social do que o de classe mais baixa. "O capital físico (recursos naturais) e o capital humano (competências educacionais e profissionais) representam a principal fonte das explicações avançadas pelos economistas para as diferenças no sucesso e no fracasso dos imigrantes" (CHISWICH, 1970; BORJAS, 1987; REINERS, 1985), citado por PORTES (1999, p. 8). Tal como referimos, as situações de inactividade correspondem a $13,7 \%$ do total das situações levantadas, neste estudo.

\section{PARTICIPAÇÃO E INTEGRAÇÃO}

Foram analisados os níveis de participação e de integração dos indivíduos em estudo, quer no país de acolhimento, quer no país de origem. O conceito de integração designa“...les divers processus par lesquels les immigrés comme l'ensemble de la population réunie dans une entité nationale participent à la vie sociale" (SCHNAPPER, 1993, p. 99). O problema da integração está implícito na sequência do processo migratório. "Na origem, porque são os processos de desintegração, tanto no plano social como sistémico, que favorecem a constituição 
do fluxo; no destino, porque a estabilização da presença dos imigrantes, .... requer reconstrução, pelos imigrantes, dos modos da sua inclusão na ordem interactiva local, e compatibilização, .... desses modos de inclusão com as características das sociedades de destino enquanto estados-nação" (PIRES, 2003, p. 4). Qualquer "meio tem formas de organização e de relação socioculturais peculiares. Ao imigrante está subjacente um trabalho de adaptação ao novo meio que o recebeu, tendo as redes sociais como principal alavanca. Quanto mais baixas forem as competências formais e os recursos instrumentais disponíveis pela população imigrada, maior é a probabilidade de esta recorrer à construção da integração, às redes que suportaram a sua deslocação, prolongando a sua existência no destino. PORTES (1999, p.3) constata que "o processo de adaptação não culmina necessariamente na assimilação à cultura e sociedade receptoras, pode antes orientar-se em direcções fundamentalmente distintas que incluem: (a) o regresso ao país de origem; (b) o surgimento voluntário de enclaves étnicos; (c) a segregação racial dos imigrantes por parte da sociedade receptora e o seu cofinamento involuntário a um sistema de castas". No presente estudo, foi possível avaliar o grau de conhecimento dos inquiridos acerca de instituições públicas da sua região de origem. Notamos que, em $58,4 \%$ dos casos, os inquiridos têm algum conhecimento de instituições de Portugal e do seu concelho de origem. As autarquias são as instituições que os sujeitos inquiridos mais bem conhecem, sendo por eles apontadas, em $75,7 \%$ dos casos. Por outro lado, as associações empresariais, por si só, apenas foram referidas 4 vezes $(3,9 \%)$, mas, em referência conjunta com as anteriores, congrega $20,4 \%$ dos casos (21 respostas plurais).

Outro índice expressivo da participação dos inquiridos é o desempenho de algum cargo político ou de responsabilidade a nível local, sendo pelo menos aquele que mais propicia actividades públicas para os emigrantes (sobretudo para aqueles que emigraram para um país da União Europeia)."Para os governos dos países emissores, os seus emigrantes tornam-se cada vez mais importantes, ... como fonte de remessas, de investimentos e de contribuições políticas..." (OSTERGAARD-NIELSEN, 2001; LEVITT, 2001b; ITZIGSOHN ET AL., 1999, cit. PORTES, 2006, p. 219). Constatamos que a esmagadora maioria dos inquiridos não exerceu qualquer tipo de cargo político, em Portugal, com 97,1\% (266 casos) e este aspecto representa uma realidade apenas para 8 inquiridos. Destes, metade desempenha esta função na Junta de Freguesia da sua área de residência; os restantes, noutros organismos não especificados. Estas proporções são praticamente iguais no que concerne aos cargos desempenhados no país de imigração, com 96,7\% (igualmente 266 casos). Os restantes desempenharam uma função nas Juntas de Freguesias do país de acolhimento - 3 casos (37,5\%) e 8 $(62,5 \%)$ noutras instituições, revelando-se a participação directa dos inquiridos extremamente baixa em qualquer um dos países considerados. 
Os dados obtidos são menos reveladores da não participação quando é considerada a filiação em associações ou cooperativas. No país de acolhimento, $33,8 \%$ dos inquiridos são membros de uma associação. Os tipos de associação são de cariz desportivo em $48,9 \%$, sendo as associações culturais o segundo tipo mais representado, de pertenças com $35,1 \%$ dos casos. As associações têm um papel decisivo na afirmação dos imigrantes na sociedade que os acolhe, quebrando, de algum modo, a situação de exílio (ALMEIDA, 1975). Ainda segundo ALMEIDA (1987) "... o emigrante tenta reproduzir no lugar onde passa a viver tudo aquilo que pode do mundo que deixou" (ALMEIDA, 1987, p. 250). Através das associações, os emigrantes reproduzem costumes, festividades e outras tradições típicas do seu local de origem, funcionando como fonte dos laços afectivos a Portugal, (ROCHA-TRINDADE, 1981).

Presenciamos que a participação em associações é menos importante nos países de origem do que nos países de imigração. Em Portugal, apenas 13,5\% dos inquiridos pertencem a uma associação. As associações desportivas surgem com $54,1 \%$ dos casos e as associações culturais com 32,4\%, (total de 37 casos considerados). Podemos concluir que a residência acaba por ter importância no associativismo activo dos emigrantes; a presença e a participação determinam de, alguma forma, as expressões e os contextos em que este se desenvolve.

\subsection{Lealdade ou pertença}

Os percursos emigratórios também levantam questões sobre temas como a lealdade ou a pertença, uma vez que os emigrantes acabam por ter uma vivência prolongada no país de acolhimento mas com frequentes visitas a Portugal. E, quando colocada a questão aos inquiridos, estes afirmaram, em 62,0\% (163 casos), se sentirem mais ligados ao país de origem, apresentando como justificação principal possuírem sentimentos de patriotismo, de afecto e de identificação com Portugal. Por outro lado, em 38,0\% dos casos, a lealdade recaiu sobre o país de imigração, com uma motivação relacionada com aspectos práticos da vida e do quotidiano, tais como, melhores condições de vida ou de trabalho, para $24,2 \%$ ( 57 casos), e duração da estadia para $14,8 \%$ (35 casos). RUIZ, (1995:6) refere-se à vivência dividida por que passam os imigrantes, reflectindo uma situação ambivalente entre duas culturas - a do país de origem e a do país acolhedor. Apesar de existir uma maioria de sujeitos com uma ligação ainda focalizada nas origens, a inclusão de outros factores, tais como a duração da migração ou a integração familiar e profissional nos países de acolhimento, parece alterar a lógica de pertença e de lealdade dos emigrantes. Para o subconjunto diferenciado da nossa amostra - os lusodescendentes -, 15 das 19 respostas obtidas apresentam maior lealdade para com o país de acolhimento / origem.

SCHNAPPER (1993, pp. 299-301), e no atinente aos lusodescendentes, afirma 
que se pode falar de uma dupla referência identitária ${ }^{1}$ mas nunca de uma dupla pertença; através da família, os lusodescendentes mantêm laços com o país de origem dos seus progenitores, podendo falar-se, no entender de Schnapper, de uma dupla referência,"...la participation à la vie colective n'a pas les même sens que les séjours de vacances, .....ou les relations de nature sentimentale qu'ils continuent souvent à entretenir avec les pays d'origine de leurs parents" (SCHNAPPER, 1993, p. 78). Verificamos que o sentimento de pertença a Portugal, por parte dos lusodescendentes inquiridos, é uma realidade para apenas 4 casos, 21,1\%. Como motivos apresentados para justificar este sentimento de pertença, sobressai o nascimento e a origem como vector principal de ligação ao país escolhido, com 15 respostas, - 78,9\%. É de salientar igualmente que o segundo motivo, com $21,1 \%$ das respostas, é a duração da estadia e a vivência no país de origem.

Esta relação de pertença está claramente representada quando a análise se cruza com a naturalidade dos sujeitos. O sentimento de ligação focaliza-se em Portugal. O sentimento de pertença do inquirido varia também sensivelmente com a duração da emigração. Uma proporção relativamente superior dos sujeitos que mais tempo estiveram fora do país de origem, revela ter um maior sentimento de ligação ao país de acolhimento $(39,5 \%$ e $46,6 \%$ para os que estiveram mais de 16 anos fora do país, contra 21,6\% e 22,7\% para os de menos de 15 anos de percurso migratório). Esta ligeira diferença é confirmada pelos testes estatísticos aplicados (valor de Qui quadrado de Pearson de 14.4, significância inferior a 0,05 de 0,010; como valor adicional observamos uma significância do Phi e do Goodman And Kruskal tau que varia entre 0.010 e 0.009 , associada a valores de 0.038 e 0.047 , o que, numa escala de 0 al, é de extremamente fraca dependência). Desde logo, concluímos, apesar de existir esta relação entre a duração da emigração e o sentimento de ligação, que esta não é o sinónimo de uma regra sólida e obrigatória, sendo apenas uma ligeira variação sem alterar o sentido ou a força da ligação dos sujeitos ao seu país de origem.

\section{CONCLUSÃO}

A progressão profissional e o percurso laboral dos emigrantes são geralmente o ponto de ancoragem sobre o qual se apoiam os seus projectos, as suas aspirações sociais ou mesmo a simples prossecução das condições económicas mínimas para a sua sobrevivência e das famílias. Evidenciamos que o percurso migratório teve repercussões importantes nas profissões exercidas pelos inqui-

\footnotetext{
1 "A identidade ......trata-se de um processo adaptativo que estabelece uma certa estabilidade, coerência, uma permanência na vida cognitiva e afectiva do indivíduo e, correlativamente, permite a adaptação deste à mudança" (Neto, 1986b:283).
} 
ridos, registando-se mobilidade social horizontal, uma vez que estes, em Portugal, maioritariamente ligados à agricultura por conta de outrem, integram, no país de acolhimento, principalmente funções de assalariados dependentes na construção civil, no comércio e na hotelaria.

No entanto e corroborando o estudo de PORTES (1999), no respeitante ao enclaves étnicos, alguns inquiridos impõem-se no país de acolhimento, com algum empreendedorismo, exercendo actividades por conta própria, constituindo o auto-emprego uma alternativa ao mercado de trabalho secundário, promovendo este a incorporação do emigrante no país de acolhimento e a mobilidade social, com fortes benefícios para os seus descendentes.

Os emigrantes têm aprendido a gerir, com a ajuda das redes sociais, o espaço transnacional como uma forma de contornar os obstáculos. Refutamos a perspectiva tradicionalista da teoria das migrações, quanto aos modos de incorporação dos imigrantes, ao defender a assimilação destes no país de acolhimento, cortando os laços de ligação à sua terra natal. Os percursos emigratórios também levantam questões referentes a temas como a lealdade ou a pertença, uma vez que os emigrantes acabam por ter uma vivência prolongada no país de acolhimento, mas com frequentes visitas a Portugal. A maior parte dos inquiridos sentem-se mais ligados ao país de origem, apresentando, como justificação, o patriotismo, o afecto e a identificação com Portugal. Por outro lado, em 38\% dos casos, a lealdade recai sobre o país de imigração, com uma motivação relacionada com aspectos práticos da vida e do quotidiano, tais como, melhores condições de vida ou de trabalho e ainda a duração de estadia. Para o subconjunto diferenciado da nossa amostra, os lusodescendentes apresentam maior lealdade para com o país de acolhimento/origem. Para justificar o sentimento de pertença, sobressai o nascimento e a origem como vector principal de ligação ao país escolhido, seguindo-se a duração de estadia e a vivência no país de origem.

O problema da integração do emigrante está implícito na sequência do processo migratório: na origem, porque são os processos de desintegração, tanto no plano social como sistémico, que favoreceram o fluxo emigratório; no destino, está subjacente um trabalho de adaptação ao novo meio que os recebeu, sendo as redes que suportaram a sua deslocação a principal alavanca da adaptação, prolongando a sua existência no destino. Os emigrantes em estudo movem-se no espaço interfronteiras internacionais e entre culturas e sistemas sociais, adoptando estratégias de vida com reconhecimento de múltiplas afiliações e identidades. 


\section{REFERÊNCIAS BIBLIOGRÁFICAS}

ARroteiA, J. (1993): A emigração portuguesa - suas origens e distribuição. Lisboa, Livraria Bertrand, col. Biblioteca Breve, vol. 79.

BORJAS, G. (1987): «Self-selection and the Earning of Immigrants» in American Economic Review, 77, pp. 531-533.

BORJAS, G. (1990): Friends or Strangers: The Impact of Immigrants on the U.S. Economy, New York, Basic Books.

Chevallier, P. (2001): «Dynamiques tertiaires de l'espace rural», Tese de doutoramento referenciada em Revue d'Économie Régionale et Urbaine, 3, pp. 510-514.

CHISWICK, B. (1978): «The Effect of Americanizations on the Earnings of foreign Born Men» in Journal of Political Economy, 86, pp. 897-921.

GonçALves, Maria Ortelinda ET AL. (2007): «Multiple Citizenship: Case Studeies Among Individual Citizens in Portugal» in Pirkko PITKAANEN and Devorah KALEKIN-FISHMAN (Eds.), Multiple State Membership and Citizenship in the Era of Transnational Migration, Sense Publishers, Rotterdam/Taipei.

GONÇALVES, Maria Ortelinda (2009): «Migrações e Desenvolvimento», Tese de Doutoramento, Os Portugueses no Mundo, colecção 2, Editora Fronteira do Caos e CEPESE.

GONÇALVES, Maria Ortelinda (2009): «A emigração legal no Concelho de Boticas, (1960/88) - Caracterização profissional e mobilidade» in Nas Duas Margens Os Portugueses No Brasil, Porto, Edições Afrontamento, CEPESE, colecção 24, pp. 465-478.

KoOSTERman, R. (2000): «Immigrant Entrepreneurship an Institutional Context: a Theoretical exploration» in J. RATH (ed.), Immigrant Businesses, The economic political environment. Londres, Macmillan Press, pp. 90-160.

LEVIT, P. (1998): «Local-Level Global Religion: The Case of U.S. - Dominican Migration», in Journal for the Scientific Study of Religion, 37, pp. 74-89.

Light, I. \& GolD, S. (2000): Ethnic Economies, San Diego e Londres: Academic Press.

NETO, F. (1986): «A adaptação psico-social e regresso ao país natal dos migrantes portugueses em França», in Psicologia, Vol.I, pp. 30-55.

Neto, F.(1993): Psicologia da Migração Portuguesa, Lisboa: Universidade Aberta.

PEIXOTO, J. (1993): «Migrações e mobilidade: as novas formas de emigração portuguesa a partir de 1980» in NizZA DA SIlVA, BAGANHA, MARANHÃo e PEREIRA (orgs.), Emigração/imigração em Portugal: Actas do Colóquio Internacional sobre emigração e imigração em Portugal, (Séculos XIX e XX). Lisboa, Editorial Fragmentos, pp. 278-307.

PIORE, M. (1979): Birds of Passage. Migrant Labor and Industrial Societies, Cambridge, Cambridge University Press.

PorTes, A. (1999): Migrações Internacionais - Origens, Tipos e Modos de Incorporação, Oeiras, Celta Editora.

PORTES, A. (2006): Estudos sobre as Migrações Contemporâneas - Transnacionalismo, empreendedorismo e a segunda geração, Lisboa, Edições Fim de Século.

RochA-TRINDADE, M. B. (1981): «Aspectos Humanos e Culturais da Emigração Portuguesa», in Nova Renascença, 6, pp. 169-175. 
RUIZ, M. (1995): Solidão. Satisfação com a vida e outros aspectos sócio-psicológicos em jovens de origem migrante frequentando o sistema de ensino português. Dissertação de Mestrado. Porto, Universidade Aberta.

SASSEN, S. (1989): «New York City's Informal Economy» in A. PorTES, M. CASTELLS, e L. A. BENTON (orgs.), The Informal Economy: studies in Advanced and Less Developed Countries, Baltimore, The Jonhns Hopkins: University Press.

SCHNAPPER, D. (1991): La France de l'intégration, Sociologie de la Nation en 1990. Paris, Gallimard.

STEYAERT, C. \& KATZ, J. (2004): «Reclaiming the space of entrepreneurship. In society: geographical, discursive and social dimensions», London: Entrepreneurship \& Regional Development, vol. 16, MAI. 